\title{
História e historiografia da democracia ateniense
}

\author{
History and historiography of Athenian democracy \\ Histoire et historiographie de la démocratie athénienne \\ Histoire et historiographie de la démocratie athénienne
}

José Antonio Dabdab Trabulsi[1]

MOSSÉ, Claude. Regards sur la démocratie athénienne. Paris: Perrin, 2013. 234 p.

\begin{abstract}
laude Mossé sempre demonstrou grande interesse pela política ateniense na Antiguidade, desde sua famosa tese de 1962 (La fin de la démocratie athénienne. Paris: PUF) até o livro aqui em questão, passando pelo que talvez seja seu livro mais lido, Histoire d'une démocratie: Athènes (Paris: Seuil, 1971) e por Politique et société en Grèce ancienne: le modèle athénien (Paris: Aubier, 1995), entre muitos outros que tratam do tema de forma mais ou menos direta. Temos então aqui toda uma vida de meditação sobre a democracia ateniense.
\end{abstract}

Desde a introdução ("Démocratie d'hier et démocratie d'aujoud'hui", p. 7-11), a motivação contemporânea se exprime com vigor:

A democracia está na ordem do dia. Políticos, professores universitários, jornalistas fazem dela um dos temas privilegiados de suas reflexões, interrogando-se sobre seu funcionamento onde ela existe, sobre suas possibilidades de instauração onde ela ainda não foi experimentada. Foi para instalá-la no Oriente Médio que foram feitas as expedições militares no Afeganistão e no Iraque. Foi para fazê-la triunfar que as multidões saíram às ruas para se manifestar em Kiev e em Minsk. É por ela que se enfrentam, na África, grupos cujos objetivos temos por vezes dificuldades de compreender, onde subsistem antagonismos provenientes de um longo passado. Isso tudo mostra que se trata de uma das questões dominantes deste início de século XXI, na medida em que dela também depende a solução de outros problemas que se apresentam ao mundo de hoje, sejam eles econômicos, ecológicos ou demográficos. (p. 7)

Mas o que ocorre é que essa ideia de estudar a democracia antiga no interesse da democracia contemporânea não é simples de articular em termos de pertinência da análise. É por isso que fico feliz em constatar que o ponto de vista de Mossé é o mesmo que defendi em meu livro de 2006 sobre a

Resenha recebida em 27 de janeiro de 2016 e aprovada para publicação em 10 de março de 2016.

['] Professor do Departamento de História da Universidade Federal de Minas Gerais (UFMG) - Belo Horizonte - Brasil.

E-mail: dabdabtrabulsi@fafich.ufmg.br 
questão (Participation directe et démocratie grecque: une histoire exemplaire?. Besançon: PUFC. p. 9-19). Mossé, com efeito, apresenta a questão da seguinte maneira:

Validade do princípio majoritário e formas que pode tomar a participação na tomada de decisão são os problemas que se colocam a todos os que se preocupam com o declínio das democracias no mundo atual. Isso significa dizer que a democracia grega pode fornecer um modelo aos homens de hoje? A essa questão não há resposta evidente, pois seria fazer abstração dos 25 séculos que nos separam da Atenas de Péricles. Por outro lado, pode ser interessante tentar compreender o funcionamento desse sistema político e da ideologia que o justificava, mas também lembrar o olhar lançado sobre ele ao longo dos séculos. Pois, das questões que a democracia ateniense levantou ao longo da história, podem ser tiradas lições suscetíveis de ajudar em um renascimento da democracia, hoje mais necessário do que nunca. (p. 9)

\section{Essa ideia de estudar a democracia antiga no interesse da democracia contemporânea não é simples de articular em termos de pertinência da análise}

A autora começa muito naturalmente pela história da democracia ateniense (Capítulo 1: "L'invention de la démocratie", p. 13-45). Procede a uma apresentação clara das principais etapas da formação da democracia ateniense, de Sólon a Péricles, passando por Clístenes e Efialtes. Em seguida (p. 27-34), explica os conceitos-chave do regime, liberdade e igualdade, e lança algumas das bases da estrutura social da cidade. Explica também (p. 34-45) o funcionamento da democracia, suas instituições, suas práticas, suas principais figuras, terminando o capítulo com uma questão: "E isso nos traz de volta à questão essencial relacionada com o funcionamento da democracia ateniense, a da realidade do poder do démos. Questão difícil, pois para responder a ela precisaríamos dispor de elementos que nos faltam" (p. 43). Nesse ponto da análise, podemos considerar que ela se inclina por uma hipótese "intermediária" nesse debate espinhoso; mas voltará mais adiante no livro, de forma um pouco menos neutra, sobre esse ponto.

No Capítulo 2 ("Le rejet de la démocratie", p. 47-65), a autora trata desse fenômeno em dois tempos: inicialmente, uma explicação política das duas revoluções oligárquicas do final do século V (p. 48-54) e, depois, uma análise do questionamento acerca da democracia entre os teóricos antigos, sejam eles oradores, políticos, historiadores ou filósofos. Mais para o final da seção, dá uma atenção especial à questão das relações entre a democracia e a lei. Esse capítulo tem por mérito e por resultado mostrar claramente que a 
democracia nunca foi coisa consensual em Atenas, e isso apesar de seu sucesso e de sua grande estabilidade no tempo. Ela também não deixa de tomar partido no debate acerca do fim do regime: "A derrota, diante de Felipe inicialmente, de Antípatros depois, levou, senão ao desaparecimento total, pelo menos ao declínio da democracia" (p. 65).

Chegamos ao terceiro tempo "antigo" da questão: "L'oubli de la démocratie" (Capítulo 3, p. 67-87). Sob esse título, a autora apresenta a história política de Atenas nas épocas helenística e romana, nas quais a democracia foi várias vezes derrubada, restabelecida, mas, sobretudo, modificada e, no fim, desnaturada. Apresentando Atenas tal como ela aparece em autores importantes (Políbio, Cícero, Plutarco, entre outros), Mossé começa nesse capítulo uma mudança de abordagem, passando da forma suave da história da democracia em Atenas para o papel da lembrança deixada pela democracia ateniense na história, e, para começar, na cultura antiga "pós-clássica":

Como vemos, a imagem da democracia ateniense permanece majoritariamente negativa no conjunto do mundo romano. Quando se evoca a grandeza de Atenas, ela não é relacionada com o regime democrático, e sim com alguns homens que ocuparam a liderança da cidade e que, de Sólon a Fócion, souberam garantir a liberdade e criar as condições de sua autoridade no seio do mundo egeu. E com frequência é lembrada a ingratidão dos atenienses em relação a esses homens, enquanto a decadência de Atenas é ligada a um gosto desmedido pelo luxo e pelos espetáculos, o que já era denunciado por Platão em sua época. (p. 87)

A parte sobre a "posteridade da democracia ateniense" começa no Capítulo 4 ("De la Renaissance aux Lumières", p. 89-116). No que se refere ao Renascimento, a autora examina o movimento comunal na Itália, quando os gregos e os romanos se tornaram de novo "pertinentes", mas quase sempre com uma imagem negativa da democracia. Mas a atenção atribuída a Tucídides e a Plutarco tornava outra vez possível discutir a questão. Na França do Renascimento e na Inglaterra elisabetana, países que viviam então o reforço do poder real, a questão se desloca para aspectos morais, acerca do heroísmo, e sobre certos temas políticos, mais do que sobre os regimes. Ela faz em seguida uma análise das "Luzes", na qual retoma alguns de seus trabalhos mais antigos (entre os quais seu livro L'Antiquité dans la Révolution française. Paris: Albin Michel, 1989), assim como trabalhos de N. Loraux, P. VidalNaquet e F. Hartog. A questão da política antiga é estudada em Montesquieu, na Enciclopédia, e, sobretudo, em duas obras fundamentais, Le voyage du jeune Anacharsis en Grèce, do abade Barthélemy, e Les recherches philosophiques sur les Grecs, de Cornélius de Pauw. Este último é especialmente importante para a questão da democracia, por ser talvez a primeira obra moderna a exprimir uma opinião global mais positiva sobre o regime ateniense, ao ponto de seu autor receber, em 1792, juntamente com Thomas Payne e George 
Washington, a cidadania francesa por ter "servido à causa da liberdade e preparado a libertação dos povos” (p. 115).

Depois das Luzes, as revoluções (Capítulo 5, "Les temps des révolutions", p. 117-140). Esse capítulo é dedicado às duas Revoluções, Americana e Francesa. O horizonte republicano desses dois processos históricos colocou a Antiguidade romana, espartana e ateniense na ordem do dia. Apesar de uma cultura "antiga", "pagã", bem menos intensa na América do que na Europa, os Pais Fundadores dos Estados Unidos examinaram e discutiram os Antigos, John Adams em especial. Mas, de forma geral, foi a desconfiança de um Hamilton em relação ao poder popular que prevaleceu. Em relação à Revolução Francesa, a questão será mais complexa e vai variar fortemente de acordo com as etapas da Revolução. Mossé, retomando seu livro sobre a questão, segue as mudanças na imagem de Atenas da Constituinte ao Terror, até a reação termidoriana. Grande atenção é dedicada a dois autores, Desmoulins e seu elogio da liberdade de palavra dos atenienses, e Chateaubriand e seu desencanto com a república. Mossé nos mostra abundantemente de que forma a Antiguidade, a política, a democracia, o povo foram uma espécie de "linguagem" durante o processo revolucionário.

\section{A democracia nunca foi coisa consensual em Atenas, e isso apesar de seu sucesso e de sua grande estabilidade no tempo}

No capítulo seguinte (Capítulo 6, "L'avènement de l'Athènes 'bourgeoise', de Benjamin Constant à Fustel de Coulanges et Max Weber", p. 141-164), Mossé apresenta a formação da visão "burguesa" sobre a Atenas antiga e sua democracia, desde o texto fundador de Benjamin Constant sobre as diferenças entre a liberdade dos Antigos e a liberdade dos Modernos até o verdadeiro "império" exercido durante meio século pelo trabalho de Gustave Glotz sobre a Cidade grega (a partir de sua publicação em 1928). As etapas dessa construção são muito bem apresentadas: Fustel e sua obsessão em "libertar" os Modernos da influência dos Antigos, J. Burckhardt e o tema das relações entre igualdade política e desigualdade social, M. Weber e sua denúncia da tirania da maioria (ainda que ele identificasse uma "racionalidade" no regime ateniense). De uma reflexão mais filosófica passamos ao nascimento de uma história grega "profissional”, com G. Grote e G. Droysen. Foi Grote quem instalou a democracia no centro da história ateniense e grega. Em Droysen, o que interessa é a decadência do regime, a fim de "explicar" Felipe e Alexandre. Da mesma forma, Mossé explica o nascimento de uma verdadeira "Atenas francesa”, em Victor Duruy e Gustave Glotz. Em Duruy, o segundo império, mistura de poder pessoal e sufrágio universal, encontra seu eco na Atenas democrática dominada por Péricles. Em Glotz, é o tema da "cidade", tomado de 
empréstimo a Fustel (mas de certa forma contra ele, pelo abandono do tema do génos como fonte das instituições e da cidade), que vai ser o fio condutor, mas uma cidade "democrática" (dois terços do livro são dedicados ao período da democracia), e um século V que será escolhido como acmè da história ateniense, grega e quiçá humana. É a França democrática, elitista e liberal que se lê no espelho da Atenas clássica. E eu só posso subscrever as palavras de Mossé, quando ela diz:

Lendo a Cidade grega de Glotz, não podemos deixar de pensar na França desses anos que antecedem a crise de 1929. E medimos até que ponto o historiador, mesmo o mais apegado a uma "verdade" fundada em um conhecimento aprofundado dos "fatos", não deixa de ser muito marcado por sua época. (p. 164)

Ao longo do século XIX, e até Glotz, a Europa liberal encontrou um novo equilíbrio e uma nova utilidade à Grécia clássica, a Atenas e à sua democracia. Uma imagem bastante idealizada, na qual o imperialismo ateniense se encontrava justificado por seus efeitos "civilizadores" e onde a escravidão se encontrava desculpada por sua "doçura" em Atenas. Na segunda metade do século XX, essa imagem será destruída pelo trabalho inovador de Moses Finley; e Mossé, que o conheceu bem, vai retraçar a vida, a obra e a contribuição historiográfica do grande historiador com grande fineza naquele que é, em minha opinião, o melhor capítulo do livro (Capítulo 7, "Le 'moment' Finley: une mise en question de la vulgate”, p. 165-188). E isso em vários domínios: sua posição de certa forma intermediária no debate sem fim sobre o "modernismo" ou o "primitivismo" da economia antiga; seu reconhecimento do fato imperialista ateniense em uma relação orgânica com a democracia; sua afirmação do fato de que a civilização grega foi construída (was based on) sobre a escravidão; as relações de novo orgânicas entre escravidão e democracia em Atenas. E, apesar disso tudo, uma defesa clara do "modelo" ateniense em termos de participação política efetiva, em termos do papel desempenhado pelo povo miúdo nos assuntos coletivos, no controle dos dirigentes da cidade por parte dos cidadãos, e pela amplitude da liberdade de palavra. Ela recoloca todas as análises de Finley nos quadros de sua vida pessoal ("caça às bruxas" nos Estados Unidos dos anos 1950; insuficiências da democracia representativa). Vale realmente a pena citar Mossé de forma um pouco mais longa quanto a isso:

A obra de Finley teve impacto considerável na Europa, tanto na Europa Oriental quanto na Europa Ocidental, e nos Estados Unidos, onde ele foi convidado a dar conferências desde 1964 em muitas universidades, inclusive naquela da qual havia sido afastado, Rutgers. A partir de uma pesquisa sobre os marcos hipotecários na Atenas do final da época clássica, ele logo alargou seus centros de interesse, tanto cronológicos quanto espaciais. Mas, no que se refere ao objeto deste trabalho, ninguém contribuiu mais que ele para a elaboração de uma imagem positiva da democracia ateniense, essa democracia escravista que 
atribui aos membros da comunidade dos cidadãos um poder de participação nas tomadas de decisão único na história da humanidade. Finley foi o que poderíamos chamar um historiador "engajado". Ele o foi politicamente, e seu percurso é comparável ao de certo número de pesquisadores de sua geração que, seduzidos pela análise marxista, dela se afastaram quando ela foi confiscada por uma ortodoxia estreita, mas conservando certos métodos de questionamento do marxismo. Por isso mesmo, ele deveria sofrer as críticas tanto dos "tradicionalistas", fechados em uma ideologia que se queria "humanista", quanto pelos defensores de um marxismo puro e duro. (p. 187-188)

Chegamos ao Capítulo 8 ("La démocratie athénienne aujourd'hui", p. 189214), no qual Mossé retorna à justificação de sua análise neste livro: "A crise que conhece a democracia contemporânea suscita um renovado interesse pela experiência ateniense. Enquanto o estudo das línguas antigas recua no conjunto do mundo ocidental, paradoxalmente nunca o 'modelo' ateniense conheceu tal florescimento de análises, feitas não apenas pelos especialistas da Antiguidade, como também por filósofos e politólogos" (p. 189). Nesse último capítulo, Mossé examina a recepção do modelo finleyano, sua influência na França (Centro Louis Gernet), na Itália (onde o marxismo mais aberto era receptivo a seu trabalho) e, mais recentemente, nos Estados Unidos, onde ele foi especialmente retomado, transformado, discutido, contestado. É a ocasião, para Mossé, de passar em revista a historiografia recente (em um registro secular, ou seja, a dos últimos 30 anos), a fim de medir as contribuições de O. Murrey, S. Price, M. Hansen, M. Ostwald, R. Sealey e, sobretudo, J. Ober, ao qual ela dedica não menos do que 12 páginas. Partilho inteiramente sua análise e a importância que ela atribui a esse último autor, assim como sua conclusão:

Assim, ao termo de uma pesquisa que se desenvolveu por uns 20 anos, J. Ober chegou a uma conclusão que já era a de Finley. A democracia "elitista" que muitos politólogos justificavam pela capacidade reservada a uma minoria de fazer as escolhas e pela lei de ferro da oligarquia é desmentida pela própria experiência da democracia ateniense. E, mesmo levando em conta o que distingue uma pequena cidade grega de 2.500 anos atrás dos Estados contemporâneos, seu modelo de democracia "participativa" deve ser meditado pelos homens do século XXI, preocupados em dar de novo à democracia seu sentido verdadeiro. (p. 206)

Ela explica também que, ainda mais do que em política, foi em matéria de economia que a herança de Finley foi mais contestada, na França por R. Descat e por A. Bresson, alhures por J.-G. Manning e por I. Morris, entre outros.

Em uma curta conclusão (p. 215-217), explica por que é preciso medir a "distância" entre os atenienses e nós, mas afirma também a necessidade de sempre voltar ao exame da democracia ateniense com esta bela formulação 
tomada de empréstimo a W. Nippel: "Enquanto a democracia e as insuficiências de sua aplicação permanecerem sendo um tema de debate em um Estado que não é formado por deuses (Rousseau), Atenas não desaparecerá verdadeiramente da reflexão" (p. 217).

Para os que leem Claude Mossé há 40 ou 50 anos, esse livro não traz tantas novidades, salvo nos últimos capítulos. Mas esses velhos leitores são e serão cada vez mais raros. Para as novas gerações de estudantes e pesquisadores, esse último (até agora) livro de Claude Mossé pode ser uma excelente introdução ao conjunto de sua obra e de sua reflexão sobre a Grécia antiga e seu sentido para nós. E, no prosseguimento, quem sabe, a motivação para ler seus outros inúmeros trabalhos. O trabalho incansável de Mossé, e sua preocupação em sempre falar aos leitores de hoje em dia, sem jargão, em uma língua precisa, mas acessível a todos, tanto aos profissionais da história antiga quanto aos leitores comuns, me faz pensar em outra grande figura da história antiga, a belga Marie Delcourt, que, na geração anterior, sempre adotou a mesma atitude. São historiadoras a serviço de seu tempo. 